\title{
THE SELF-DIRECTED LEARNING OF WOMEN WITH BREAST CANCER
}

KATHLEEN B. RAGER

University of Oklahoma

\begin{abstract}
This study examines the self-directed learning experiences of women with breast cancer. The common elements in the experiences of 13 women who had been diagnosed with breast cancer within 3 years prior to the study were identified through analysis of semistructured interviews. The findings indicate that the participants' self-directed learning efforts were beneficial in a number of ways. Problems commonly encountered in self-directed learning included difficulty locating and evaluating resources and the affect of negative emotions. The study contributes to current understanding of self-directed learning in a crisis situation and provides valuable information on self-directed learning in an area at the intersection of adult education and health care.

Keywords: self-directed learning; breast cancer; emotions; crisis learning; patient selfeducation; women's learning
\end{abstract}

Breast cancer affects 1 in 8 American women, making it the most common form of cancer among women of all ages (Susan G. Komen Breast Cancer Foundation, 2000). For some of the 183,000 women who are diagnosed yearly, what follows is an intense process of self-education on the subject of breast cancer. The purposes of this study are to describe, from the perspectives of the participants, women's experiences with self-directed learning and breast cancer and to contribute to a broader understanding of self-directed learning in a crisis situation.

\section{SELF-DIRECTED LEARNING}

The prevalence of self-directed learning is now well established. During past years, estimates of adult participation in self-directed learning have ranged from $70 \%$ (Tough, 1973) to more than 95\% (Livingstone, 1999). Scholarly interest in this form of learning has grown considerably since the late sixties and early seventies. Although more recently there has been some decline in the number of studies and

KATHLEEN B. RAGER is an assistant professor of adult education in the Department of Educational Leadership and Policy Studies, University of Oklahoma (e-mail: kbrager@ou.edu).

ADULT EDUCATION QUARTERLY, Vol. 53 No. 4, August 2003 277-293

DOI: $10.1177 / 0741713603254030$

(C) 2003 American Association for Adult and Continuing Education 
articles on the subject (Brockett, et al., 2000), it continues to be one of the focal points for scholarship in the field of adult education (Merriam \& Caffarella, 1999).

In the present study, self-directed learning is defined as "a process in which individuals take the initiative, with or without the help of others, in diagnosing their learning needs, formulating goals, identifying human and material resources, choosing and implementing learning strategies and evaluating learning outcomes" (Knowles, 1975, p. 18). Tough's (1973) seminal work on self-directed learning projects provides a general framework for this study. Tough defined a learning project as "a series of related episodes, adding up to at least seven hours" (p. 6). His research indicates that most people engage in a minimum of 1 or 2 major selfplanned learning projects per year but that some adults undertake as many as 15 or 20. The time spent on learning projects ranged from a high of 2,000 hours to less than 100 hours.

Tough (1973) also investigated the motivations behind learning projects. He reported that these motivations included the need to make a good decision, to make something, to do something related to job, home, family, sport, or hobby, or for curiosity or enjoyment. A small proportion of learning projects were motivated by the desire to complete a certificate or degree. In Tough's research, the emphasis for all learning projects was on the anticipated use or application of what was learned. Finally, in exploring the major benefits derived from learning projects, Tough found they included pleasure or positive feelings and increased self-esteem or confidence.

More recently, Livingstone (1999) studied the extent and distribution of selfdirected learning among Canadian adults. He found that more than $95 \%$ of his sample engaged in some type of informal learning, on average for approximately 15 hours per week. Three quarters of the respondents in his general interest category were involved in learning about health and well-being.

The literature does not currently address in detail self-directed learning in a crisis situation. Brockett and Hiemstra's (1991) personal responsibility orientation (PRO) model suggests the potential importance of situational as well as personal factors in self-directed learning. PRO, an interactive model, distinguishes between instructional method processes (self-directed learning) and personality characteristics (learner self-direction), which are linked by the learner's assumption of personal responsibility. A more recent interactive model, proposed by Garrison (1997), builds on the PRO model. Garrison's model proposes the integration of "self-management (contextual control), self-monitoring (cognitive responsibility) and motivational (entering and task) dimensions to reflect a meaningful and worthwhile approach to self-directed learning" (p. 18). Self-management deals with learner control and shaping of the contextual conditions so that goals and objectives can be reached. Self-monitoring involves the ability to use a range of learning strategies and the ability to reflect on one's thinking. The motivational aspect includes what triggers the self-directed learning activity and what sustains the participation. 


\section{BREAST CANCER AND SELF-DIRECTED LEARNING}

The link between self-directed learning and personal health seems like a natural one given the current state of the health care industry. Some critics have argued that insurance companies are making medical decisions, not doctors (Cowley \& Turque, 1999). Personal responsibility and involvement in treatment decisions, it can be claimed, are essential in this climate. Mills and Sullivan (1999) characterized this new environment as the "growth of consumerism in health care, whereby patients are now seen as consumers with rights to information and active participation in their own care."

Moreover, technological advances have created treatment options in many areas, including breast cancer. A lumpectomy is now a viable choice as the research shows that mastectomy and lumpectomy are equally successful under certain circumstances (Bisel, 1996). Patients, therefore, are often faced with critical choices. Doctors, operating in an environment of increased litigation, also face new pressures. Information must necessarily play a critical role in making treatment decisions. However, a literature review of the information-seeking and decision-making preferences of patients concludes that in spite of the emphasis placed on information provision by political, professional, and ethical bodies, patients remain dissatisfied with their ability to make informed decisions (Degner, et al., 1997).

A diagnosis of cancer has been characterized as a traumatic experience (Dunlop, 1998; Landmark \& Wahl, 2002). Recent initiatives attempt to address its impact more holistically. For example, psychosocial oncology integrates psychological, social, behavioral, spiritual, and ethical aspects of cancer treatment. However, the literature indicates that access to psychosocial services varies widely despite growing need and demand among cancer patients for such services (Ross, Boesen, Dalton, \& Johansen, 2002; Simpson, Carlson, \& Trew, 2001). Additionally, there continues to be some skepticism about the beneficial effect of such interventions. For example, Ross et al. (2002) maintained that such effects have yet to be substantiated by credible research studies.

A tremendous amount of research examines women's experience of breast cancer. Some of this research focuses on topics of relevance to self-directed learning. For example, studies of the experience of breast cancer (Dunlop, 1998; Landmark \& Wahl, 2002), of patient information seeking (Arora et al., 2002; Brown, Koch, \& Webb, 2000; Mills \& Sullivan, 1999), of coping (Kirkland, 1995; Lyke, 1998), and studies of treatment decision making (Bisel, 1996; Degner et al., 1997) validate the importance of learning to cancer patients. However, the term self-directed learning is seldom if ever used in such research, and clearly the studies are not specifically focusing on the patients' self-education. Nevertheless, it is present as an important factor in the patients' experiences. Other relevant studies indicate that emotions influence patients' opinions of their doctors and their ability to recall information (Shapiro, Boggs, Melamed, \& Graham-Pole, 1992). 
Only two studies were located that focus directly on breast cancer and selfdirected learning. Murphy-Ende (1996) studied the use of a patient computer education program and the relationship of self-efficacy, self-directed learning, and health value in women. Her results suggest that there is a relationship between selfdirected learning and self-efficacy.

The second study relating self-directed learning and breast cancer is in some ways similar to the present study. Alexander (1997) explored the self-education of 10 Alaskan breast cancer patients. She found a strong relationship between learning and healing as well as between mind and body. All of her participants used random or unplanned learning processes and most sought to complement traditional medicine with alternative methods. Alexander's study, however, differs from this investigation in several ways. For example, participant characteristics, most important the time since diagnosis, were not held constant in the Alexander study. The initial diagnosis of breast cancer for the participants ranged from 3 to 28 years before the study began, raising some concerns about participants' accuracy in recalling relevant learning experiences. The interviews were not audiotaped and transcribed for analysis, leaving open the possibility that potentially important information was not documented.

In summary, the current literature on self-directed learning and breast cancer is insufficient. Missing from the adult education literature on self-directed learning is research that describes the impact of a crisis situation on the self-education process. What is missing from the medical literature is research that takes a holistic view of the self-directed learning experiences of patients. This study addresses both of these gaps and provides valuable information on self-directed learning where the fields of adult education and health care intersect. The primary question that guided the study was: Are there common motivations, process elements, resources, and outcomes in the experiences of breast cancer patients who use self-directed learning in regard to their disease? It was hoped that the study would contribute to a broader understanding of self-directed learning in a crisis situation.

\section{METHOD}

A qualitative research approach was used in this study. Purposeful sampling (Patton, 1990) was employed to locate participants who would be potentially rich sources of information about self-directed learning and breast cancer. Participants were all from the Wichita, Kansas, area and were identified through local chapters of the American Cancer Society, the Susan G. Komen Breast Cancer Foundation, a local gynecologist, and three Wichita breast cancer support groups. A 10-year breast cancer survivor who was active in the local breast cancer network served as an important source of referrals. Interviewees had to meet the following criteria: female, English speaking, and within 3 years of breast cancer diagnosis, and having engaged in a minimum of 7 hours of self-directed learning about breast cancer. 
Screening of potential participants using the selection criteria was done by telephone. Only one woman who met the criteria declined to participate because she was not comfortable revisiting her experiences. A number of women who were interested in participating were eliminated because they were more than 3 years from diagnosis. No one who was approached for participation used self-directed learning for less than 7 hours.

Individual interviews were conducted by the researcher. The number of interviewees was not predetermined. Data were collected until the point of saturation was reached (Lincoln \& Guba, 1985). This occurred after 13 interviews. At that time, the researcher determined that no new information was forthcoming. Interviews with the 13 participants ranged in duration from 1 to 3 hours with an average length of 1 hour and 45 minutes. Follow-up meetings used to verify information and for member checking ranged from 30 minutes to 2 hours.

A semistructured interview format following an interview guide was used to gather data for the study. Each interview was tape-recorded and then transcribed by a professional transcriptionist. The resulting 367 pages of interview transcripts were analyzed using the constant comparative method (Lincoln \& Guba, 1985) to identify the common patterns in the breast cancer and self-directed learning experiences of the participants. The strategies used to ensure the credibility of the findings of this study were prolonged engagement, peer debriefing, referential adequacy, and member checking (Lincoln \& Guba, 1985).

Data analysis began with the first interview (Merriam, 1998). An outline was developed for each interview transcript using words, phrases, and in some cases entire sentences to capture meaning (Boyatzis, 1999). Page numbers were included in the outlines to facilitate referral to the original data. The areas under investigation, as reflected in the interview questions, served as organizing categories; they included motivations, learning strategies, resources, problems, time, and outcomes. The outlines were then coded and comparisons were made across samples. Coding was repeatedly modified and verified using the original transcripts until it was felt that the common elements in the data had been captured. Thick description was used in writing up the study so that the participants' voices could be heard in the presentation of the data and to make more explicit the connections between the actual interview data and the conclusions of the researcher (Holloway, 1997).

\section{FINDINGS}

The women in this study were chosen as participants because self-directed learning was a critical aspect of how they coped with their breast cancer. Table 1 presents salient characteristics of respondents, including age, occupation, level of education, type of cancer, and hours devoted to self-directed learning (up to the time of the interview). The findings are organized according to the original guiding categories of motivations, learning strategies, resources, time, problems, and outcomes. 
TABLE 1

Participant Information Summary

\begin{tabular}{|c|c|c|c|c|c|}
\hline Participant & Age & Occupation & Education Level & Type of Cancer & $\begin{array}{c}\text { Hours } \\
\text { Spent } \\
\text { Learning }\end{array}$ \\
\hline Ann & 48 & Food service worker & High school & Lobular carcinoma & 173 \\
\hline Barbara & 52 & Retired manufacturing & High school & Did not know & 768 \\
\hline Cora & 66 & Retired nurses' aid & High school, technical training & Did not know & 458 \\
\hline Diane & 53 & Nurse administrator & Master's degree & Infiltrating ductal & 500 \\
\hline Eileen & 48 & Wage and labor investigator & High school, 54 college hours & Inflammatory & 144 \\
\hline Fran & 55 & Psychologist & Master's degree & Carcinoma in situ & 1,392 \\
\hline Gloria & 42 & Technical consultant & Bachelor's degree & Invasive ductal carcinoma & 39 \\
\hline Helen & 56 & Teacher & Master's degree plus & Intraductal comeda & 179 \\
\hline Inez & 54 & Teacher & Master's degree plus & Intraductal carcinoma & 642 \\
\hline Joyce & 43 & Retail receiving manager & High school & Did not know & 200 \\
\hline Karla & 57 & Student & High school & Ductal carcinoma & 268 \\
\hline Linda & 47 & Hospital administration clerk & Bachelor's degree & Did not know & 26 \\
\hline Marcy & 62 & Homemaker & High school & Lobular carcinoma & 409 \\
\hline
\end{tabular}




\section{Motivations for Learning}

Three common motivations for self-directed learning about breast cancer could be identified in the interviews. These motivations were the desire to overcome fear associated with the diagnosis, the desire to understand what was happening to them so they could best help themselves, and the need to learn so that they could make informed choices regarding their treatment or to confirm their doctors' treatment choices. Fran's explanation was typical: "I' $m$ the kind of person that always has to know the answers, the why." Like most of the participants, her motives for learning were complex and involved all three motivations. She felt that it was just "more peaceful for me to know." Armed with the information she had gathered, Fran became convinced that the surgeon who had done her biopsy was not properly taking care of her. Her self-directed learning eventually led her to the Mayo Clinic where she had her mastectomy and reconstruction.

\section{Learning Strategies and Resources}

Common strategies used to learn about breast cancer were reading print materials, using the Internet, networking, and attending support groups. All of the participants were identified through contacts with various types of breast cancer support groups, and all but one attended fairly regularly.

Print materials. Print materials were used by all of the participants. The sources of the print materials varied; some were obtained from doctors' offices, libraries, bookstores, friends, the American Cancer Society, and Reach to Recovery (a program of the American Cancer Society). Inez explained why print materials were the most helpful to her: "I could pick them up and read them when I wanted to instead of having to talk to somebody when I could reach them." Others mentioned that print materials allowed them to go at their own rate and to revisit a reference as other issues arose later in their treatment.

The Internet. Although the Internet was identified as a major resource in their self-directed learning, not everyone using it had positive experiences. Diane, who is a nurse, remarked, "I think getting information off the Internet, while it's a good resource, I think you have to be very careful. I think there's good stuff and bad stuff." Both Diane and Gloria used the Internet to access the National Cancer Institute. Gloria commented,

The stuff on the Internet showed me that what my doctors were telling me and what I was reading in the National Institute material, the guidelines, were the same. I was able to read the studies that were the basis of those guidelines and recommendations. 
For some of the participants, access to computers and their computer skills developed as they went along. Eileen reported,

I get real frustrated with the Internet, because I pull up something and then there's like a ca-billion sites and I just want the relevant ones. I'm not real good at narrowing them down yet and I get real frustrated.

Karla had a very negative experience with chat rooms on the Internet:

I was horrified on the Internet. I went to a breast cancer survivors group and we were talking on the Internet. It seems that the most horrific situations are put on the Internet. Sometimes you don't even know if they're true and this is something I don't think people are aware of or even think about. You don't know who's putting this out there. But, I read some stuff and I thought, "I don't have a chance in hell!" and I thought, "I'm not going there anymore. This is not what's going to happen to me." So I had to stop doing the Internet thing.

Networking. All of the participants networked to gain information about which doctors were the best, what treatment was like, what resources were helpful, what other survivors had experienced, and to obtain emotional support. Family members, friends, acquaintances, friends of friends, doctors, nurses, pharmacists, and survivors were mentioned frequently as part of the network that the women used in their self-directed learning.

The story of how Eileen selected her surgeon is an example of this type of networking. She was given her diagnosis at 10:00 a.m. on a Friday in her primary-care physician's office. Because of the nature of her inflammatory breast cancer, time was critical. Her doctor gave her a list of three surgeons and told her to select one by 2:00 p.m. so they could schedule her mastectomy as soon as possible in the following week. Eileen explained,

So I left the office looking at these three names that meant absolutely nothing to me. ... I remembered we had played golf in a Scotch foursome the Sunday night before with a retired radiologist and his wife at the country club. So I called him. . . I I said, "I don't really know you, but I met you Sunday." And I said, "I have a list of surgeons and could you give me a recommendation because I'm flying blind here." And so he put them in order, number one, number two, and number three. Then he said, "Why don't you call your radiologist? I like him a lot. See who he would recommend?" Well, I called him. Come to find out his wife has breast cancer, so they've been going through a lot of the same thing. He'd been down this path. So he also put the names in order. ... So I had all this done by 2 o'clock. . . I called my doctor and I picked the surgeon I wanted. She called me back in 15 minutes to say this doctor would see me at 9 o'clock the next morning.

Support groups. Support groups were also identified as an important resource. According to Helen, they are valuable 
not only for information, but for the moral support I get from them. As one of them said, "It's kind of a sisterhood." If we have a question or problem we talk about it. Someone there has probably had the same one and says what they have done about it. So do I sometimes. So it's like a mutual, symbiotic relationship.

Linda said that the support group was her most helpful resource: "The support group was the best. Just seeing people in different stages of treatment was helpful. They were really very positive. It relieved some of my fears." Fran reported that the first time she cried about her breast cancer was a year after diagnosis when she attended her first support group meeting:

I had finally found a spot where I could have support. I had my husband's undying support. I had my daughter's, but I didn't have my friends and I didn't have my family. You need that place where it's okay, a place where you feel safe. That is what the group gives you. We talk about breast cancer. We laugh about it. We cry about it. We tell funny things. We tell bad things.

It was clear that the self-directed learning of the participants was not solitary. The person who was most helpful to them varied from participant to participant. Their answers included themselves, their husbands, survivors, friends, community volunteers, nurses, and ministers.

Time

There were several aspects of time that characterized the respondents' selfdirected learning: when learning began, the absence of planning, and the amount of time spent.

When learning began. In most cases, the learning process began after diagnosis, but with some recovery time needed for the initial shock. The amount of delay ranged from a few hours to a few weeks. Barbara described her reaction:

My doctor was very good with us, but when he said the word cancer, my mind went totally blank. I didn't hear anymore of the conversation, but I could see him talking with my husband and he was drawing pictures and explaining what had to be done.

Helen's husband started researching immediately:

And he was going on the Internet and getting all this information and he said, "Now don't you want to read these?" And I said, "No, not yet." And he was getting really irritated with me. Well, I just needed a couple of weeks to get it resolved in my life and see what I had to do before I started reading.

Fran described herself as being in a fog at first, "Those 2 or 3 weeks are kind of a mumble jumble." 
Absence of planning. None of the 13 women indicated that they planned their learning to any large extent. For the most part, they were reacting to their situations. Fran explained, "I don't think a person has the time to plan. Anything that says those two words, breast cancer, you just latch onto." Eileen said,

It was real haphazard. It was just kind of what you could find, where if somebody handed you something or somebody in conversation said you might want to try this or

look at this Web site or do this or that kind of thing.

Amount of time spent. The most difficult question for all participants to answer was how much time they had spent learning about breast cancer since their diagnosis. The estimates ranged from a low of 26 hours to a high of 1,400 hours and are presented in Table 1. Two things became clear. First, the time spent on self-directed learning greatly exceeded Tough's (1973) criteria of a minimum of 7 hours; second, it was difficult for participants to reconstruct exactly how much time was spent.

\section{Problems}

The participants reported having a wide range of problems in their self-directed learning efforts. Two common problem areas were locating and evaluating resources and coping with emotions.

Resources. Some of the respondents reported difficulty in locating resources. Diane mentioned this even though she had the advantage of her nursing background. Helen said,

I was having trouble finding out about my particular kind of breast cancer because it's not one of the common kinds. So initially I had a little trouble because I went through some books that didn't have much on it at all.

Inez complained of incomplete information. After her lumpectomy, for example, she was released without being given a drainage bag holder or being shown how to use one. Inez said,

I didn't know I was supposed to get a little bag. So John and I went back to the doctor a couple of days later, and I had the drainage tube stuck in the pocket of my shirt. Well, the nurse about died when she saw that! They found a used bag that they could give me and were very apologetic. I hadn't read anything about it so I didn't know.

Diane, Eileen, Fran, Karla, Linda, and Gloria mentioned the difficulty they had in distinguishing between good and bad resources including doctors, print materials, and Internet sites. Eileen was particularly frustrated because her doctors would not help her evaluate the alternative approaches discovered in her reading. Karla com- 
plained that "there's not enough material that's really positive. Most of the stuff is really negative and really gloom and doom."

Emotions. The second major problem in their self-directed learning experiences concerned the impact of their emotions. Gloria explained,

I didn't feel like I had a lot of time. In that process, I wasn't dealing with emotions, and every once in a while they would surface and get in the way. The vast amount of information and the quickness that I had to absorb it in were problems. I had too much information. I became overwhelmed by "paralysis of analysis." That was all complicated by emotions I think.

Some of the women talked about being "depressed," "numb," "in a fog," or "totally petrified." Joyce expressed it this way: "The best analogy is that I'm a VCR and about September 30th somebody pushed the pause button and we haven't released the pause button yet."

Inez recounted an emotional breakthrough when she was finally able to express what she was feeling. She had been busy being strong and "keeping a stiff upper lip." On one occasion during the time she was undergoing radiation treatments, she broke down sobbing as she looked at her breast in the bathroom mirror:

I can remember just collapsing on the bathroom floor sobbing. I remember going in and lying down on the bed and curling up in a fetal position. I told John that I needed to talk and that I didn't want him to say anything. I was finally able to admit that I was totally petrified. Once I admitted that I was fine.

Karla talked about her reaction to the breast cancer chat room on the Internet. "If I read it now, it might be totally different. Now I'm passed the real horrible pain of this and the horrible fear, but when you're in such gripping fear, it just was so sad." Even the support groups were difficult at times. Eileen reported,

It's real rugged when you're in the middle of trying to get through it the first time and you see women there with recurrences. Because you're thinking, "If I go through all this, am I going to be like them? So is there any point to doing this?"

Barbara, Eileen, Fran, Gloria, and Karla all identified the need for psychological support in coping with breast cancer. They reported that support groups and volunteer organizations are in place for breast cancer patients and are helpful in this regard, but that they had to find them on their own. For them, the connections of these resources to the medical treatment community were uneven and in some cases nonexistent. Joyce characterized her experience by saying, "So I haven't had a good experience here; no information, no help, and it just seemed like nobody cared. I don't like to hear somebody fall through the cracks because I know how that feels. I was there." 


\section{Learning Outcomes}

Five common outcomes of self-directed learning could be identified in the interviews. These outcomes were increased self-confidence, the desire to use what was learned to help other breast cancer patients, increased confidence in treatment decisions, lessening of the emotional stress and fear associated with breast cancer, and increased knowledge of what was happening to them.

An increase in self-confidence was mentioned frequently as an outcome of the self-directed learning experience associated with breast cancer. Some of the participants characterized it as increased assertiveness. For most, this increase in self-confidence led to reaching out to help other women with breast cancer. In discussing how self-directed learning had changed her, Ann commented on feeling "much stronger, much more confident, and much more assured in myself, because nobody could do this for me. I had to do this myself." She was active in helping other women who have been diagnosed and said,

In my heart, I think that's something I need to do. By learning I've become more competent. More like I can talk to other people and tell other people, a testimonial almost. I just want to be there to give them support and share what I have learned and how they can learn some things too, if they want to.

Inez observed,

Well, I think all learning changes you. No matter what you're learning, you're not the same person you were before. I think it changed me for the better. I'm a stronger person. I know more so I can ask more. I'm more informed.

Eileen's learning led her to reach out to help others:

I think I became just so much more aware. When you get diagnosed with something like this and you're learning lots of things, you realize how important it is that other people share with you. You realize that you in turn have a responsibility to do that at the other end.

Another common outcome was the confidence that the learning engendered in their treatment decision making. This had been identified as the motivation for learning and so it was not surprising that it was one of the most commonly cited outcomes. Ann said, "And it may be the generation they grew up in, but those doctors aren't gods. You can dispute what they're saying. You have a right to ask why and how come." She used her learning to participate in the decisions made regarding her treatment. Sometimes the outcome of increased confidence in treatment decisions was manifest as validating their doctors' recommendations rather than in making decisions for themselves. Ann, Barbara, Helen and Marcy cited examples of how this was part of their experience. 
The fourth common outcome was that their self-directed learning helped them emotionally. Cora found that the learning made her less afraid of breast cancer. "It took away the fear." She also talked about her participation in the support group and how comforting it was to know that she was not alone. "We're all in the same boat. Everybody is there for one another." A number of the participants spoke of the breast cancer journey as an emotional roller coaster. Eileen reported, "Sometimes when you're losing it, you tend to beat yourself up about it. Well, the stuff that you read lets you have a little license to do some of that and know that it's okay." Joyce was very sure that her learning had helped her emotionally:

I was more frightened before I started reading, because the more informed I got the more I knew this was what I had to do. And it took away a little of the fear. Not all of it, but it took away some of it. I mean there's still fear there. There will always be fear.

The fifth outcome was not stated directly by the women, but rather was implied by their other comments. As a result of their learning, they were more knowledgeable about breast cancer and about what they were going to experience in their breast cancer treatment. Although this was identified as a motivation for their learning, it was not specifically mentioned as an outcome.

Joyce was the only participant in the study who reported that she was not satisfied with the outcome of her self-directed learning. "I was a little disappointed. I don't know what I was looking for other than an answer to tell me I didn't need a mastectomy. But it wasn't there." All 13 women felt that they had benefited from their efforts.

\section{DISCUSSION}

The self-directed learning experiences described by the breast cancer patients in this study support previous findings from literature in both adult education and health care. At the same time, the findings shed new light on the experience of selfdirected learning in a crisis situation.

\section{Self-Directed Learning Process}

The women in this study indicated that self-directed learning was beneficial to them in this context and that the benefits went beyond their initial intentions. There were three common motivations for their learning: to lessen their fear, to help make or validate treatment decisions, and to understand what was going to happen in their treatment. However, there were five common outcomes from their learning. They included successfully addressing their initial reasons for learning and two unintended results: a growth in self-confidence and the desire to help other breast cancer patients. For the participants in this study, their self-directed learning helped them under these difficult circumstances. 
The findings are largely consistent with Tough's (1973) original process description. The women's learning activities all exceeded his criteria of a minimum of 7 hours in 6 months, and similar to Tough's findings, their motivations included the need to make a good decision. Also consistent with Tough's findings was the emphasis on making use of what they learned to help themselves, their positive feelings about their learning, their increase in self-esteem, and the fact that their learning was not solitary.

\section{Self-Directed Learning Models}

Perhaps the most significant contribution of this study is the information it provides regarding the impact of emotions on the self-directed learning process in what may be termed a crisis situation. The PRO model (Brockett \& Hiemstra, 1991) recognizes social context as an important factor in considering self-directed learning. However, the findings of this research suggest that in some circumstances, such as a diagnosis of breast cancer, there is also an emotional context that must be considered. That emotional context, it may be argued, is distinct from the personal characteristics or personality of the learner; rather, it is inherent in the crisis situation in which the self-directed learning takes place. R. G. Brockett (personal communication, October 3, 2000) has indicated that consideration of emotional aspects such as those experienced by the women in this study is implied but not dealt with specifically in the literature on self-directed learning. As reported by the participants, emotions interfered with their ability to begin learning and their ability to make use of some resources, influenced their reactions to some of the information they did find, and impaired their ability to stay focused. Unlike prior descriptions of selfdirected learning, their experiences were, as Gloria stated, "complicated by emotion." Efforts to understand the impact of a crisis situation such as a breast cancer diagnosis on self-directed learning must consider the pervasive influence of emotion on the experience.

Garrison's (1997) model encompasses some aspects of the self-directed learning experiences of the women in this study. Self-management-a key component of his model—includes goal management, learning methods, support, and outcomes. In this study, the four common learning methods of networking, attending at support groups, reading, and using the Internet were self-management aspects of the self-directed experiences of the participants. Self-monitoring, according to Garrison's interactive model, is the "process whereby the learner takes responsibility for the construction of personal meaning" (p. 24). It includes both reflective learning and critical thinking. Self-monitoring was reflected in this study when the participants interpreted and evaluated information to make treatment decisions as well as in their conclusions that they now had an obligation to help other newly diagnosed women.

The third aspect of Garrison's (1997) model is motivation. According to Garrison, it includes both the entering motivation (the decision to learn) and the task 
motivation (the persistence required to stay on task). The clear communication of the women in this study regarding their motivations for learning about breast cancer and the estimates of the time they spent learning reflect the presence of both of these motivational aspects from Garrison's model.

Although Garrison dealt with the affective state of the self-directed learner in discussing the entering motivation of the learner, this does not appear to represent the emotional context of the learning as reported by the women in this study. This study establishes the reality of that emotional context. It suggests that emotions not only play a role in the entering and sustaining motivations to learn but are also the filter through which all aspects of the process are experienced.

\section{Emotional and Psychological Needs}

The findings of this study also suggest that self-directed learning was instrumental in meeting the emotional and psychological needs of the participants. Their experiences suggest that these needs were not addressed as part of their medical treatment, in spite of the fact that medical literature identifies breast cancer as traumatic (Dunlop, 1998; Landmark \& Wahl, 2002) and the fact that attempts are being made to address the psychosocial aspects of the diagnosis (Simpson, Carlson, \& Trew, 2001). It was generally through their self-directed learning that the women in this study came to know about community resources available to assist breast cancer patients. They then became part of the local breast cancer network, which was a source not only of information but also of emotional and psychological support.

The most emotional moments of the interviews took place when the participants talked about those people who had and those who had not provided support during their breast cancer journeys. Clearly, this was a very meaningful aspect of their experiences. They also expressed their strong desire to stay connected through volunteer work with other women who develop breast cancer. On one hand, the women reported how helpful support groups and survivors were in meeting their informational, psychological, and emotional needs. On the other hand, they expressed how important it was to them to "give back" by helping others as they continued in their recovery from breast cancer. The benefits of the support to both the giver and the receiver are implied by the findings of this study and support similar conclusions drawn by Lyke (1998).

Emotion or affect was also present in the women's evaluations of their doctors. Unlike the women in Dunlop's (1998) study, most of the women in this research found that their doctors were very receptive to their questions and invited, or in some cases required, their participation in decisions regarding their treatment. Consistent with other research (Shapiro et al., 1992), the women suggested that the absence of a warm, collaborative relationship with their doctors indicated a lack of concern and resulted in a loss of confidence in both the doctor and the proposed treatment. 
The women's descriptions of their experiences show that access to current, reliable, understandable, and relevant information was critical to the success of their self-directed learning efforts and yet was problematic as well. The participants struggled with not being able to locate specific information, with material that was too technical for them to understand, and with concerns about the reliability of information and sources. Of particular interest was their expressed difficulty with materials that were too frightening to be useful to them. In this case their emotions blocked their use of certain resources. They specifically expressed a desire for positive materials.

The findings suggest that for these women, self-directed learning was beneficial. In fact, the benefits exceeded their expectations. What was distinctive about the descriptions of their experiences was the pervasive impact of emotions. As reported by the participants, emotions interfered with their ability to begin learning and their ability to make use of some resources, influenced their reactions to some of the information they did find, affected their evaluations of their doctors, and impaired their ability to stay focused. However, it was through their self-directed learning that they found their way to resources that helped in meeting their emotional and psychological needs.

\section{SUGGESTIONS FOR FURTHER RESEARCH}

Further research is needed to determine the proportion of breast cancer patients who use self-directed learning, to identify the factors that distinguish them from those who do not, to provide additional empirical documentation regarding benefits they derive from the experience, and to explore strategies to most effectively support their efforts, especially in consideration of the emotional context of their learning experiences. Finally, the findings indicate that the self-directed learning experiences of the women in this study were difficult but beneficial. Their descriptions provide valuable information to adult educators, health care providers, the breast cancer support community, and others facing similar health crises.

\section{REFERENCES}

Alexander, T. L. (1997). Learning and healing: Self-education by cancer survivors (Master's thesis, University of Alaska-Anchorage, 1997). Masters Abstracts International, 36(01), 0014.

Arora, N. K., Johnson, P., Gustafson, D. H., McTavish, F., Hawkins, R. P., \& Pingree, S. (2002). Barriers to information access, perceived health competence and psychosocial health outcomes: Test of a mediation model in a breast cancer sample [Electronic version]. Patient Education and Counseling, 47, 37-46.

Bisel, D. J. (1996). Knowledge, sources used and factors considered in the surgical treatment decisions of women with breast cancer (Master's thesis, Grand Valley State University, 1996). Masters Abstracts International, 34(05), 1915.

Boyatzis, R. E. (1999). Transforming qualitative information. Thousand Oaks, CA: Sage. 
Brockett, R. G., \& Hiemstra, R. (1991). Self-direction in adult learning: Perspectives on theory, research, and practice. London: Routledge Kegan Paul.

Brockett, R. G., Stockdale, S. L., Fogerson, D. L., Cox, B. F., Canipe, J. B., \& Chuprina, L. A. (2000, February). Two decades of literature on self-directed learning: A content analysis. Symposium conducted at the 14th International Self-Directed Learning Symposium, Boynton Beach, Florida.

Brown, M., Koch, T., \& Webb, C. (2000). Information needs of women with non-invasive breast cancer [Electronic version]. Journal of Clinical Nursing, 9(5), 713-722.

Cowley, G., \& Turque, B. (1999, November 8). Critical condition. Newsweek, 133(9A), 58-61.

Degner, L. F., Kristjanson, L. J., Bowman, D., Sloan, J. A., Carriere, K. C., \& O’Neil, J. (1997). Information needs and decisional preferences in women with breast cancer [Electronic version]. Journal of the American Medical Association, 277(18), 1485-1492.

Dunlop, A. A. (1998). Learning from women with breast cancer: An ethnographic study (Doctoral dissertation, University of Victoria, 1998). Dissertation Abstracts International, 59(12), 4367A.

Garrison, D. R. (1997). Self-directed learning: Toward a comprehensive model. Adult Education Quarterly, 48(1), 18-33.

Holloway, I. (1997). Basic concepts for qualitative research. Oxford: Basil Blackwell.

Kirkland, B. J. (1995). Psychological adjustment to breast cancer: Congruence of locus of control and information and decision making participation. Dissertation Abstracts International, 56(11), 6395B. (UMI No. AAINN01459)

Knowles, M. S. (1975). Self-directed learning. Chicago: Follett.

Landmark, B. T., \& Wahl, A. D. (2002). Living with newly diagnosed breast cancer: A qualitative study of 10 women with newly diagnosed breast cancer [Electronic version]. Journal of Advanced Nursing, 40, 112-121.

Lincoln, Y. S., \& Guba, E. G. (1985). Naturalistic inquiry. Beverly Hills, CA: Sage.

Livingstone, D. W. (1999). Exploring the icebergs of adult learning: Findings of the first Canadian survey of informal learning practices. Canadian Journal for the Study of Adult Education, 13(2), 49-72.

Lyke, J. R. (1998). Coping experiences of women living with breast cancer (Master's thesis, University of Alaska-Anchorage, 1998). Masters Abstracts International, 37(01), 0238.

Merriam, S. B. (1998). Qualitative research and case study applications in education. San Francisco: Jossey-Bass.

Merriam, S. B., \& Caffarella, R. S. (1999). Learning in adulthood: A comprehensive guide. San Francisco: Jossey-Bass.

Mills, M., \& Sullivan, K. (1999). The importance of information giving for patients newly diagnosed with cancer: A review of the literature [Electronic version]. Journal of Clinical Nursing, 8(6), 631642.

Murphy-Ende, K. (1996). The relationship of self-directed learning, self-efficacy, and health value in young women with cancer using a computer health education program (Doctoral dissertation, The University of Wisconsin-Madison, 1996). Dissertation Abstracts International, 57(04), $2482 \mathrm{~B}$.

Patton, M. Q. (1990). Qualitative evaluation and research methods. Newbury Park, CA: Sage.

Ross, L., Boesen, E. H., Dalton, S. O., \& Johansen, C. (2002). Mind and cancer: Does psychosocial intervention improve survival and psychological well-being? [Electronic version]. European Journal of Cancer, 38(11), 1447-1457.

Shapiro, D. E., Boggs, S. R., Melamed, B. G., \& Graham-Pole, J. (1992). The effect of varied physician affect on recall, anxiety, and perceptions in women at risk for breast cancer: An analogue study. Health Psychology, 11(1), 61-66.

Simpson, J. A., Carlson, L. E., \& Trew, M. E. (2001). Effect of group therapy for breast cancer on healthcare utilization [Electronic version]. Cancer Practice, 9(1), 19-26.

Susan G. Komen Breast Cancer Foundation. (2000). Breast health: Facts and figures. Retrieved from www.breastcancerinfo.com/bhealth/html/facts_and_figures.asp

Tough, A. (1973). The adult's learning projects: A fresh approach to theory and practice in adult learning (2nd ed.). Toronto, Canada: Ontario Institute for Studies in Education. 